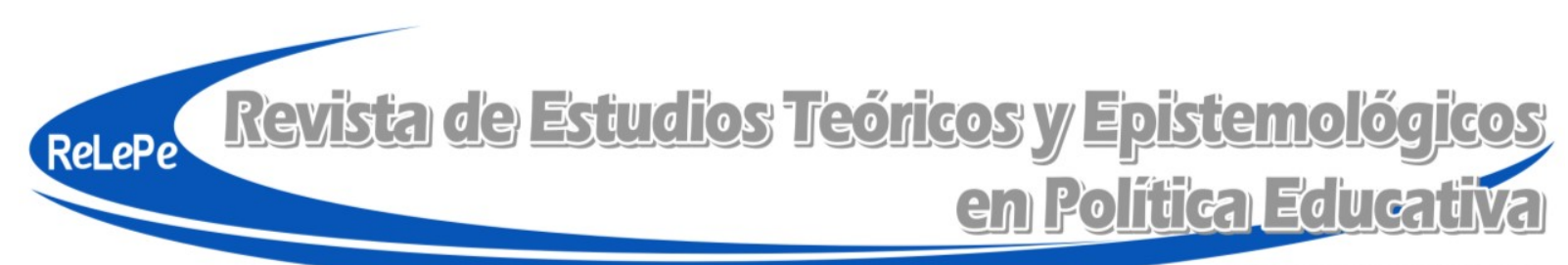

ISSN 2409-3696

DOI: $10.5212 /$ retepe.v.2.016

\title{
As teorias da gestão escolar e sua influência nas escolas públicas brasileiras
}

\author{
Ângelo Ricardo de Souza \\ Universidade Federal do Paraná, Brasil \\ angelo@ufpr.br
}

\begin{abstract}
Resumo: Este artigo teórico busca cotejar as teorias clássicas e críticas da gestão escolar no Brasil com o cotidiano deste campo nas escolas públicas do país, contemporaneamente. O trabalho se debruça sobre os escritos de Carneiro Leão, Querino Ribeiro, Anísio Teixeira e Benno Sander, na perspectiva clássica, e de Miguel Arroyo, Fátima Félix e Vitor Paro, na perspectiva crítica, buscando sintetizar o as ideias principais dessas escolas de pensamento. A partir de tal síntese, o estudo contrapõe os elementos mais emblemáticos daquelas teorias com os estudos mais recentes do campo, que demonstram estar mais articulados à realidade empírica das escolas brasileiras. $\mathrm{O}$ artigo conclui indicando que há um grau de desconexão entre as teorias clássicas e críticas com a gestão escolar contemporânea, mas, ao mesmo tempo, é possível se perceber algumas relações e influências, tendo em vista a forte veia prescritiva da teoria no campo da gestão escolar.
\end{abstract}

Palavras-chave: Gestão escolar. Administração escolar. Teorias clássicas. Teorias críticas.

\section{School management theories and their influence in Brazilian public schools}

\begin{abstract}
This theoretical article seeks to compare the classical and critical theories of school administration in Brazil with the contemporary public schools management. The work focuses on the writings by Carneiro Leão, Querino Ribeiro, Anísio Teixeira and Benno Sander, in the classical perspective, and Miguel Arroyo, Fátima Félix and Vitor Paro, in the critical perspective, seeking to synthesize the main ideas of these schools. From this synthesis, the study contrasts the most emblematic elements of those theories with the most recent studies in this field, which seem to be more articulated to the empirical reality of the Brazilian schools. The article concludes by indicating that there is a degree of disconnection between classical and critical theories with the contemporary school management, but at the same time it is possible to perceive some relationships and influences, considering the strong prescriptive vein of the school management theory.
\end{abstract}

Keywords: School management. School administration. Classical theories. Critical theories.

\section{Las teorías de la gestión escolar y su influencia en las escuelas públicas brasileras}

Resumen: Este artículo teórico busca cotejar las teorías clásicas y críticas de la gestión escolar en Brasil con el cotidiano de este campo en las escuelas públicas del país, contemporáneamente. El trabajo se centra en los escritos de Carneiro León, Querino Ribeiro, Anísio Teixeira y Benno Sander, en la perspectiva clásica, y de Miguel Arroyo, Fátima Félix y Vitor Paro, en la perspectiva crítica, buscando sintetizar las ideas principales de esas escuelas de pensamiento. A partir de tal síntesis, el estudio contrapone los elementos más emblemáticos de aquellas teorías con los estudios más recientes del campo, que demuestran estar más articulados a la realidad empírica de las escuelas brasileñas. El artículo concluye indicando que hay un grado de desconexión entre las teorías clásicas y críticas con la gestión escolar contemporánea, pero al mismo tiempo es posible percibir algunas relaciones e influencias, teniendo en vista la fuerte vena prescriptiva de la teoría en el campo de la gestión escolar.

Palabras-clave: Gestión escolar. Administración escolar. Teorías clásicas. Teorías críticas. 


\section{Introdução}

Este texto apresenta uma reflexão teórica a partir da contribuição de autores do campo da gestão/administração escolar ${ }^{1}$ (AE) no Brasil. O escopo do trabalho é apresentar, sinteticamente, elementos centrais do pensamento de alguns autores emblemáticos da Escola Clássica e da Escola Crítica da Administração Escolar (SOUZA, 2007), e articular tais ideias com aspectos da gestão das escolas públicas brasileiras atualmente. Assim, a questão que nos colocamos a responder aqui é: Há relação entre as teorias mais consolidadas no campo da administração escolar no Brasil e a gestão escolar no cotidiano atual das escolas públicas?

Inicialmente, para buscar os elementos centrais das teorias mencionadas, resumimos a compreensão do campo de conhecimento circunscrito pelas referidas escolas de pensamento. E, dentro delas, identificamos os autores que mais bem expressam o pensamento predominante nos tempos e na história da AE. Da escola clássica, trabalhamos com Antônio Carneiro Leão, José Querino Ribeiro, Anísio Teixeira e Benno Sander. Na escola crítica, escolhemos trabalhar com Miguel Arroyo, Maria de Fátima Félix e Vitor Henrique Paro. São váriosos autores que poderiam ser acrescidos a um ou a outro período ${ }^{2}$, mas esses foram escolhidos porque se encontram como as principais citações de seus colegas, contemporâneos inclusive, como expressões das escolas de pensamento em questão.

Ao final, buscou-se produzir uma síntese das ideias dos teóricos em questão, cotejando-a a uma análise de elementos mais hodiernos da gestão escolar, a partir da literatura mais recente.

\section{Administração Escolar e Administração: O Pensamento Clássico da Gestão Escolar no Brasil}

Um dos primeiros trabalhos produzidos no Brasil sobre a administração escolar é de autoria de Antônio Carneiro Leão, de 1939. A edição que aqui trazemos é a terceira, de 1953, mais compacta que as anteriores. Sem dúvida, trata-se de obra muito importante sobre a administração escolar no país não apenas por ter sido o primeiro esforço de sistematização na área, mas porque foi, por muito tempo, um dos mais citados referenciais para o estudo da AE e da educação comparada, campos que por muito tempo atuaram próximos. E esta proximidade é a marca do trabalho de Leão, na medida em que procura articular os conceitos e exemplos da administração escolar nos diferentes países e sistemas de ensino. Trata-se, portanto, de um trabalho de administração escolar comparada.

A tônica do texto é a apresentação de uma organização de um sistema de ensino, na qual as funções, deveres e relações hierárquicas são bastante explícitas. Assim o texto passa pelas figuras do diretor de educação, superintendente de escolas, etc., até chegar no diretor de escola, o qual deve ser sempre um professor,

\footnotetext{
${ }^{1}$ Neste trabalho, gestão e administração escolar são tomados como sinônimos, mesmo sabendo que a literatura do campo reconhece diferenças entre os termos. A razão para tanto está articulada à compreensão que temos que se trata mais de significados que foram cambiando com o tempo do que elementos essenciais de uma ou outra expressão.

${ }^{2} \mathrm{Na}$ escola clássica, afora os quatro autores (Leão, Querino Ribeiro, Teixeira e Sander), há vários outros que a literatura tem abordado e que podem ser associados ao que chamamos de escola clássica da AE. Dentre eles, Lourenço Filho, Myrtes Alonso, Moisés Brejon, Arnaldo Niskier, João Gualberto, dentre outros. Na escola crítica, também poderíamos incluir Maria Dativa Gonçalves, Acácia Kuenzer Zung, Carlos Roberto Jamil Cury, dentre outros. Para aprofundar esta discussão, veja Souza (2007), Abdian (2010), Ribeiro; Machado (2007), Drabach (2009).
} 
com o conhecimento da política educacional de seu povo e dos deveres de administrador. [...] [O diretor] defende a política de educação estabelecida, interpreta-a, realiza-a em sua esfera com inteligência e lealdade. [...] Sua ação não se limita, porém, à administração, ela é também de orientação ou de cooperação como o orientador. Em qualquer dos casos é preciosa e indispensável. [...] É então o coordenador de todas as peças da máquina que dirige, o líder de seus companheiros de trabalho, o galvanizador de uma comunhão de esforços e de ações em prol da obra educacional da comunidade (LEÃO, 1953, p. 107-109).

Esta concepção de diretor como defensor da política educacional corresponde à ideia hegemônica à época de que o dirigente escolar é antes mesmo de suas funções de educador, um representante oficial do Estado, considerando o seu papel de chefe de uma repartição oficial (a escola pública) e, como tal, teria o dever de se comprometer com os rumos políticos da administração governamental, a qual, muito possivelmente, fora responsável pela sua indicação para assumir tal cargo.

No período da educação brasileira no qual Leão escreve seu livro havia grande necessidade de profissionalização e cientificidade e este era o reclame presente no discurso dos principais intelectuais, isto é, a escola tradicional que imperava no início do século XX precisava ser superada e a melhor forma para fazê-lo articulava a ampliação do atendimento educacional para a população com a profissionalização dos quadros docentes, sob a tutela do Estado. Para uma desejada escola para todos, havia a demanda da intervenção direta do poder público na sua condução, com vistas àqueles fins, daí que a identificação do diretor escolar com o papel de representação imediata da administração pública parece ser condizente com tal necessidade.

O texto de Leão é muito dedicado à praticidade didática, sendo voltado a apresentar alternativas no ensino da AE. Quando apresenta, por exemplo, um curso para aperfeiçoamento de diretores escolares, sugere que a gestão escolar se resume à figura do diretor, e mesmo que ele fosse auxiliado por outras pessoas, parece que o autor confunde direção e administração escolar, ou seja, o processo de identificação de problemas, de planejamento, de tomada de decisões, de acompanhamento e controle e avaliação das ações escolares é todo ele centrado na figura do diretor.

Neste sentido, processo e responsável parecem se tornar uma só coisa. E isto é reforçado com a ênfase dada ao sujeito que responde pela direção escolar: "o diretor é a alma da escola. Diž-me quem é o diretor que te direi o que vale a escola" (LEÃO, 1953, p. 134). Este diretor teria as funções de "administrador do edificio da escola; responsável pela escolba e fornecimento de material, pela bigiene escolar e infantil, pelas relaçôes sociais com a escola, pela observação e interpretação do ambiente escolar" (LEÃO, 1953, p. 135), dentre outros aspectos.

Outro texto clássico muito importante é o de autoria do Prof. José Querino Ribeiro (1952), pois representa talvez a primeira bem-sucedida tentativa no país de apresentação de um ensaio que busca ao mesmo tempo sugerir formas de organização e administração da escola e teorizar sobre esses aspectos. De início, o autor afirma que a educação pública, pela lógica de financiamento público a que está submetida, tem o dever de apresentar resultados adequados ao máximo.

A teoria da administração escolar que o autor constrói se sustenta na busca por fundamentos nas atividades próprias da escola (RIBEIRO, 1952, p. 14), o que contraria em parte a teoria da administração científica na qual Ribeiro se sustenta, ou seja, a escola apresenta aspectos que são únicos e que não podem ser desconsiderados nos processos administrativos, 
todavia, o autor reconhece que os princípios e métodos da administração científica são aplicáveis à escola, pois ela também possui aspectos muito comuns a todas as organizações.

A origem dos estudos sobre a administração pública é a responsável pelos estudos sobre a administração escolar, na opinião do autor. Aquela tem sua gênese na significativa alteração na ordem pública trazida pela prática de eleições para dirigentes públicos, o que teria provocado a necessidade de o poder público ser mais eficiente:

Agora, pois, o Estado não podia contentar-se apenas com a legitimidade do poder, precisava obter mais eficiência dos serviços. O Estado assume, então, além de suas características seculares tradicionais, mais o aspecto de uma verdadeira empresa pública de enormes proporções (RIBEIRO, 1952, p. 35).

De forma equivalente ao Estado, a escola também passa por processo de alteração sentida na sua função social, acumulando mais importância no espectro das instituições sociais (RIBEIRO, 1952, p. 37) e, correlatamente, ampliando-se a necessidade da oferta estatal dos serviços educacionais à crescente demanda da população ou das estratégias de desenvolvimento nacional:

As características do Estado Moderno (especialmente as influências das massas que lhe penetraram por todos os poros, massas de que depende porque é um Estado representativo, sustentado pela democracia de urna) fazem da estatização do ensino fonte de novos e difíceis problemas: a "escola para todos" conduz à "escola em toda parte" e, consequentemente, à "escola de todos os tipos" (RIBEIRO, 1952, p. 39).

Essas alterações históricas, de alguma forma também mencionadas por Leão, forçam a constituição de mecanismos mais organizados para a administração dos estabelecimentos de ensino, uma vez que essa instituição complexa necessitava de mecanismos intermediários que dessem conta de garantir bons resultados em um contexto que incluía as tradicionais tarefas sociais da escola, então somadas às demandas mais contemporâneas do desenvolvimento social e econômico do país.

Para Ribeiro, a AE fundamenta-se a partir da filosofia da educação, da política da educação e das ciências correlatas ao processo educativo. A partir da filosofia da educação, o autor afirma que não faz sentido "uma Administração Escolar sem fundamentação em algum esquema de objetivos e ideais postos antes e acima dela, isto é, de uma filosofia" (RIBEIRO, 1952, p. 45).

No que tange à política da educação, ou a política escolar, Ribeiro a vê como uma atividade superior às ações administrativas no sentido estrito que se passam no interior da escola, o que demonstra uma compreensão mais ampliada em relação à função da $\mathrm{AE}$, percebendo nela um papel político, de governo, que transcende o simples domínio técnico das tarefas concernentes ao ato administrativo.

O autor reconhece que a administração escolar tem a tarefa de organizar e coordenar os trabalhos escolares, a partir de informações coletadas na própria fonte dos problemas educacionais, uma vez que admite que nenhuma regulação estatal acerca dos currículos pode cercear a liberdade de condução da ação pedagógica do professor. Para tanto, é necessário um clima de ação coletiva na escola, superando-se as tradicionais formas hierárquicas da organização escolar (RIBEIRO, 1952, p. 66-67). É certo que o autor não está sugerindo a constituição de uma "gestão democrática" da escola, em termos sequer próximos aos empregados na definição desta concepção como se faz contemporaneamente, mesmo porque a expressão do pensamento à época se voltava muito mais para a identificação do dirigente escolar com a função de chefe de 
uma repartição pública organizada hierarquicamente. Todavia, é interessante observar a crítica ao modelo tradicional de organização escolar empreendida por Ribeiro, que a faz sustentando-se na necessidade de se "cientificizar" a administração escolar.

É verdade que esta preocupação com a economia deriva, em grande parte, da influência, pela qual passam os autores da época, do pensamento funcionalista na administração ${ }^{3}$ em geral. Mas a preocupação com a eficiência e a economia escolares não deixa de ser, à época, uma preocupação com a ampliação do direito à educação.

Ribeiro ainda trata de apresentar um conjunto de classificações acerca da administração escolar no que tange aos seus aspectos, tipos, processos, meios e objetivos. E quanto a esses elementos, o autor vê que a "Administração Escolar é uma das aplicações da administração geral; naquela como nesta os aspectos, tipos, processos, meios e objetivos são semelhantes" (RIBEIRO, 1952, p. 113). Mas, ainda assim a administração escolar possui características específicas. De qualquer jeito, o autor reconhece a escola como um espaço específico, ou com funções e natureza específicas. Neste sentido, e por entender a administração escolar como possuindo predominantemente uma face técnica, a compreensão e o domínio do conhecimento sobre aquela especificidade escolar, com o suporte técnico da administração geral e escolar, permitiria a solução dos problemas escolares.

O autor conclui sua obra mostrando os três problemas fundamentais para a administração escolar:

a) apreender os ideais propostos pela Filosofia da Educação para, em função deles, determinar os objetivos da escola; b) conhecer a Política de Educação para, em função dela, adotar um estilo de ação adequado; c) aproveitar as contribuições da ciência para o conhecimento dos elementos humanos envolvidos no processo de escolarização e, em função dele, empregar as técnicas mais convenientes às atividades da escola (RIBEIRO, 1952, p. 152).

Neste período clássico, contudo, o autor que mais se destaca na área é Anísio Teixeira, que ao longo de mais de 40 anos escreveu muito sobre a AE. Dentre esses muitos textos, há um em particular que nos chama a atenção, que é a transcrição de uma conferência realizada em 1961 na abertura do I Simpósio Brasileiro de Administração Escolar, na condição de Diretor do INEP, denominada "Que é Administração Escolar?". Esta conferência foi depois publicada na Revista Brasileira de Estudos Pedagógicos (1961). O pensamento deste autor é muito importante porque Teixeira foi, sabidamente, um dos maiores autores a tratar sobre a educação no Brasil em toda a sua história, e não pode ser comparado de maneira linear aos demais autores deste período da $\mathrm{AE}$ no Brasil, porque sua produção ultrapassa no tempo, no conteúdo e na abordagem deste conteúdo, os rumos apontados pelos estudos anteriormente mencionados (SOUZA, 2007). Mesmo assim, há elementos equivalentes entre o seu trabalho e os dos demais, particularmente no que se refere às críticas à escola tradicional, à necessidade de profissionalização da educação e aos reclames de incremento quantitativo e qualitativo no atendimento educacional.

O objeto do texto/conferência é, como o seu título sugere, o conceito e o estatuto da administração escolar. Já no início, o autor percebe a inexistência quase absoluta da AE no Brasil de então, uma vez que os administradores não estavam sendo preparados e a evidência de que qualquer pessoa acabava sendo dirigente escolar. As razões para tal são duas, ao seu ver: ou "os professores são tão perfeitos, que realmente não precisem de Administração" ou "as escolas sejam tão pequenas, que tais professores, perfeitíssimos, podem realizar seu trabalho em perfeito estado, digamos, de anarquia, cada um fazendo o que venba lhe parecer que deve faz̧er e resultando disso uma admirável Administração" (TEIXEIRA,

${ }^{3}$ Especialmente Taylor e Faiol e seus seguidores. 
1961, p. 84). Essas duas hipóteses são importantes para entender o seu raciocínio, porque para ele a administração escolar nasce exatamente para dar conta desses dois problemas: a) organização dos profissionais do ensino, cujas tarefas se tornam mais complexas dia-a-dia; b) organização da escola, a qual vinha se transformando em relação ao tamanho, amplitude/cobertura e também complexidade.

Teixeira considera que não há administração sem poder e que a pessoa que administra é aquela que dispõe esse poder e dos demais meios e recursos para alcançar os resultados desejados (TEIXEIRA, 1961, p. 85). Todavia, a despeito deste conceito, para o autor não há apenas um tipo de administração. De um lado está a administração da fábrica, na qual a função de administrar é máxima e a de execução é mínima, e de outro lado está a administração escolar, "na qual o elemento mais importante não é o administrador, mas o professor" (TEIXEIRA, 1961, p. 85). Aqui parece termos uma mudança de pensamento em relação aos demais autores do período clássico, pois para Teixeira a razão do trabalho do Administrador Escolar é, antes de tudo, pedagógica, centrada na figura do professor e, por conseguinte, na do aluno e no processo educativo. A chave para a compreensão dessas ideias é a competência do docente e a complexidade da instituição escolar. Essas ideias demonstram que a administração escolar é, antes de tudo, uma ferramenta a serviço do desenvolvimento pedagógico da escola e não possui uma razão própria alheia ao trabalho docente e à função educativa da instituição ${ }^{4}$.

Benno Sander é o último autor desta escola ${ }^{5}$, tendo publicado diversos trabalhos aqui e no exterior em um momento de transição e, ciente das mudanças, explorou o contexto apontando tanto as contribuições clássicas quanto a necessidade de superação dos equívocos que delas derivariam.

Nos textos que aqui exploramos, Sander procura justamente mediar as posições entre o pensamento dos primeiros autores do campo com as críticas do movimento que era então nascente (virada dos anos 1970 para 1980). O autor, ao contrário de vários de seus antecessores, não afirma que a administração da educação está contida no amplo campo da administração, sendo dela um segmento, uma especialidade, ao contrário, chega mesmo a entender a administração da educação como um processo político (SANDER, 1981, p. 45). Todavia, a forma como apresenta os conceitos e a base bibliográfica com que trabalha sugere uma compreensão do campo da administração da educação como, ainda, um terreno híbrido, no qual diferentes áreas contribuem, como demonstra o modelo de análise por ele construído. É certo que o autor reconhece que o ato administrativo é devedor da base política e pedagógica que o sustenta: "Como corolário dessa relação entre educação e política, a administração é, ao mesmo tempo, um ato pedagógico e um ato político" (SANDER, 1984, p. 151, grifos do autor). Mas esse reconhecimento parece uma alternativa para alcançar aquele objetivo de mediação. Ademais, o reconhecimento das faces política e pedagógica da administração não representa o entendimento da administração da educação como um fenômeno antes de tudo político-pedagógico.

A AE pode, segundo o autor, ser estudada sob diferentes enfoques: jurídico, organizacional, comportamental e sociológico (SANDER, 1981, p. 11). O autor discute isto transitando por diferentes trabalhos de autores brasileiros e estrangeiros, representantes daquelas diferentes perspectivas, tentado demonstrar de forma esquemática e classificatória os pensamentos desses autores, sem, contudo, tomar posição muito claramente.

\footnotetext{
${ }^{4}$ Em outro texto, Anísio Teixeira chega mesmo a afirmar que a administração escolar não é uma especialidade da administração e sim uma ação político-pedagógica, antes de tudo (TEIXEIRA, 1968).

5 Talvez pudéssemos classificá-lo como um autor na transição entre a escola clássica e a escola crítica da AE.
} 
No enfoque jurídico, traz o entendimento sobre a administração da educação até os anos de 1930, calcado na tradição do direito romano. No enfoque organizacional, o autor classifica os estudos primeiros do campo, como os trabalhos de Querino Ribeiro e de Anísio Teixeira. Neste período, surgiram os trabalhos mais importantes do campo até os anos 1980, segundo o autor, estudos esses que têm a tecnocracia como a base para a solução dos problemas das organizações, além certamente do reconhecimento da própria ideia de organização dentro do campo da educação.

No enfoque comportamental, Sander identifica os trabalhos que procuraram superar os problemas que as teorias mais clássicas da administração apresentaram, em especial no que tange aos aspectos psicossociais das organizações. Por último, o enfoque sociológico, o qual Sander observa como sendo a corrente mais recente dos estudos do campo, e para a qual os estudos jurídicos, organizacionais e comportamentais estariam migrando. É nesse enfoque, que o autor vê a presença de trabalhos que entendem a função administrativa como sendo, por essência, sociológica ou política (SANDER, 1981, p. 21). É também neste campo que o autor classifica os estudos mais críticos que serão objeto de discussão no próximo tópico deste artigo.

Para o avanço dos estudos do campo, Sander sugere uma proposta de análise e de prescrição, ao mesmo tempo, da administração da educação, denominada de Paradigma Multidimensional de Administração da Educação (SANDER, 1981, p. 31 e seguintes), que é um esquema analítico no qual são cotejadas as dimensões intrínseca e extrínseca da $\mathrm{AE}$ com as dimensões substantiva e instrumental, permitindo identificar as faces pedagógica, econômica, sociopolítica e humana nos sistemas educacionais, derivadas da interação entre aquelas dimensões.

Em outra entrada, o autor afirma que há quatro critérios de acordo com os quais a administração da educação se orienta e que estão relacionados com aquelas dimensões: "relevância (dimensão humana), efetividade (dimensão sociopolítica), eficácia (dimensão pedagógica) e eficiência (dimensão econômica)" (SANDER, 1981, p. 34). Esses critérios e dimensões se expressam na função do administrador da educação, cujas competências podem assim ser vislumbradas:

A competência humana do administrador da educação revela-se na capacidade para conceber soluções e na liderança para implantá-las sob a ótica da relevância para a plena realização dos participantes da comunidade educacional. A competência sociopolítica define o talento do administrador da educação para perceber o ambiente externo e sua influência sobre o sistema educacional e seus participantes, e a habilidade de adotar uma estratégia de ação para a efetiva satisfação das necessidades e demandas sociais e políticas do sistema educacional. A competência pedagógica do administrador da educação reflete sua capacidade para formular objetivos educacionais e para desenhar cenários e meios pedagógicos eficazes para a sua consecução. Finalmente, a competência econômica do administrador da educação refere-se à sua eficiência para otimizar a captação e utilização dos recursos e elementos técnicos e racionais a serviço dos objetivos do sistema educacional (SANDER, 1981, p. 51-52).

As principais ideias deste período, que se iniciou nos anos $30 \mathrm{com}$ o trabalho de Leão, perduraram ainda por muito tempo, sendo possível vê-las presentes em trabalhos dos anos 1970 e 1980, mas a partir de então a diminuição da influência foi sentida. A principal contribuição que esses autores trouxeram foi verdadeiramente a constituição acadêmica do campo da gestão escolar no Brasil, voltada a qualificar as definições da administração e da política escolar e preocupada com a preparação técnica e instrumental dos dirigentes educacionais e escolares, num contexto de crescente complexidade da instituição escolar. 
Afora Teixeira e Sander, os demais autores da época parecem compartilhar da base teórica da administração científica e das escolas subsequentes, como substrato para a edificação da teoria da administração escolar. A face técnica dos processos e instrumentos da gestão escolar é superdimensionada neste período, numa tentativa de dar cientificidade ao campo, mas emersa de uma concepção aparentemente ingênua (PARO, 1988), que supõe que o domínio sobre esta face é capaz de garantir bons resultados e o alcance dos objetivos institucionais.

Os diretores escolares eram compreendidos pela maioria dos autores do período como chefes da instituição escolar e figuras centrais da sua gestão, a ponto mesmo de confundir por vezes a pessoa e o processo dirigente. O imbricamento entre a direção e a política educacional também não parecia ser questão de qualquer polêmica, pois aparentemente se reconhecia como "natural" as relações políticas perfeitamente articuladas entre o diretor e o administrador do sistema de ensino. Todavia, destaca-se o reconhecimento do papel pedagógico do diretor, que se era um chefe ou um político, não deixava de ser alguém que se encontrava na escola para garantir as condições de desenvolvimento da educação.

Também parece comum, em boa parte desses estudos, a preocupação mais voltada à elaboração de ensaios, de estudos prescritivos, uma vez que voltados aos profissionais que iniciavam sua atuação dirigindo as escolas do país. Em uma frase, não eram trabalhos de pesquisa empírica. Isto, todavia, não diminui o valor das suas contribuições, especialmente porque são trabalhos que devem ser lidos considerando o seu tempo e os seus interlocutores. A crítica que se construiu a este período parece, por vezes, ignorar o avanço que estes trabalhos representaram em seu tempo, como veremos a seguir.

\section{A crítica ao pensamento clássico da Administração Escolar}

Os trabalhos que surgiram no final dos anos 1970 e início dos 1980 inauguraram uma perspectiva crítica na análise da gestão escolar. Devedores, em grande parte, do trabalho de Maurício Tragtemberg (1974) que apresenta no país talvez uma das primeiras críticas ao papel ideológico da teoria geral da administração, o foco central desses estudos se localizava no fato dos trabalhos anteriores apresentarem concepções por demais técnicas da AE, colocando-a a serviço da reprodução de um modelo de escola que não contribuía para a superação das bases capitalistas sobre as quais a sociedade brasileira estava solidificada e auxiliava a manutenção do status social, econômico e político.

São vários os trabalhos que se apresentam com essa pretensão crítica. $\mathrm{Na}$ verdade, muito da produção da área a partir desta ocasião é decorrente da perspectiva mais crítica e pode ser lida quase que como uma reprodução desta análise do começo dos anos 1980 (SOUZA, 2007). Os trabalhos mais emblemáticos, para sintetizarmos em alguns poucos, são um artigo de Miguel Arroyo (1979), a dissertação de mestrado publicada em livro de autoria de Maria de Fátima Félix (1984) e a tese de doutorado também publicada em livro de Vitor H. Paro (1988).

O artigo de Arroyo (1979) trata das relações políticas que cercam a administração da educação, procurando construir uma linha de crítica aos modelos implantados no país que procuravam, segundo o autor, torná-la uma tarefa meramente técnica e, com isto, propugnavam identificar as causas dos problemas educacionais brasileiros com razões tipicamente técnicas. Isto é, se os problemas educacionais eram ocasionados por incompetência ou incapacidade técnica, a administração científica, calcada na racionalidade da empresa privada - modelo que inspirava a administração educacional no país, resolveria esses problemas. 
Esta preocupação do autor é importante para a época e tem que ser compreendida no contexto da sua produção, pois não pode passar despercebido que à época os mecanismos normativos que o país possuía talvez não fossem suficientes para garantir minimamente o atendimento das crescentes demandas. Este quadro mais frágil nas estruturas organizativas e financeiras da educação no final dos anos 1970 é inclusive utilizado como argumento pelos propositores das reformas da administração educacional da época. De todo jeito, a questão que se coloca central para o autor é por que era dada prioridade aos procedimentos administrativos como suporte para a superação dos crônicos problemas educacionais brasileiros? A primeira possibilidade de resposta está, para Arroyo, no reconhecimento de que, por detrás dos modelos de administração da educação, havia uma concepção mais ampla de organização do estado e da economia, voltada à constituição de uma "modernização e racionalização das instituições que complementam o sistema de produção" (ARROYO, 1979, p. 37). Esta racionalização e modernização estavam voltadas à busca de uma educação para o desenvolvimento produtivo, uma vez que a educação era vista como algo cujo funcionamento era obsoleto aos olhos do mundo da produção. A lógica de importação dos modelos de administração da empresa privada para a educação localizava na própria educação as origens dos seus problemas, retirando responsabilidades macro-estruturais do mau funcionamento dos sistemas de ensino. Esta lógica é, segundo Arroyo, absolutamente política. Eis aí então sua primeira verificação da face política da administração pretensamente técnica. Esta face política se escancara quando a administração é compreendida como um exercício de mediação do poder entre os que detêm o poder de decisão e a população, sendo que, neste sentido, o papel da administração é menos de incremento da produtividade da empresa privada ou pública e é mais voltado às relações de poder da empresa. Isto leva o autor a concluir que "a insistência em apresentar a racionalidade administrativa como necessidade 'natural' ao bom funcionamento das instituicões oculta a dimensão política de todo processo administrativo" (ARROYO, 1979, p. 39).

Por fim, Arroyo se preocupa com o papel do dirigente escolar e educacional, que deve, em sua concepção, superar a pretensa neutralidade que se lhe atribuem os cursos de formação inicial e continuada e os documentos legais, percebendo a natureza política do trabalho escolar e reconstruindo análises macrossociais sobre a escola. É evidente o momento em que o autor se debruça sobre a administração escolar e da educação. Trata-se de período em que ao administrador é reclamado amplo conhecimento sobre as técnicas de gestão e organização, mesmo que com conhecimentos superficiais sobre o real objeto com o qual deveria lidar: a educação escolar e o processo educativo. A preocupação do autor é de que os dirigentes estavam pouco concentrados nos aspectos mais amplos que têm impacto na organização e gestão das escolas e dos sistemas de ensino e que são, em grande parte, responsáveis pelas causas dos problemas educacionais. Não há aqui, ao que parece, um pedido para os dirigentes não olharem a escola por dentro, e a prova disto está na passagem final do artigo quando Arroyo sugere que os cursos de formação se pautem pela formação do "educador - docente, administrador, orientador... capaz. de um fazer pensado, crítico, atento ao modelo de um homem a ser educado e às relações entre a escola e a sociedade", levando a administração da educação "a recuperar seu sentido social" (ARROYO, 1979, p. 46). Esta preocupação política do autor parece ser uma preocupação de política pedagógica, isto é, de pontuar as críticas a modelos de administração que chegavam às escolas desconhecendo as próprias escolas, desconhecendo o fazer pedagógico e as razões que deveriam movê-los. A esta preocupação se somam outros autores, como Maria de Fátima Félix.

A autora produziu trabalho de crítica aos modelos de administração escolar vigente no país até o início dos anos 1980 em sua dissertação de mestrado (1984). Este trabalho tinha como objetivo ajudar na construção "deste movimento crítico, mediante uma análise da Administração Escolar, explicitando as relações que se estabelecem entre o sistema escolar e a evolução do capitalismo" (FÉLIX, 1984, p. 12). A partir deste objetivo a autora procura deixar claro ao leitor que as análises que apresenta 
no seu livro cotejam a AE enquanto ferramenta operacional da política educacional e as relações entre esta política e o Estado. Para tanto, estabelece quatro pressupostos que norteiam o trabalho: a educação brasileira é resultante da realidade política, econômica e social do país; logo, para a compreensão da realidade educacional demanda-se a compreensão dos macrocondicionantes econômicos, políticos e sociais; a despeito do controle da classe dominante sobre a classe dominada, através da mediatização promovida pela superestrutura jurídico-política, não se trata de um controle absoluto, uma vez que é inerente ao capitalismo a contradição social; possíveis novas formas de organização do Estado são decorrentes de mudanças econômicas, políticas e sociais, as quais também determinam novas formas de confronto entre as diferentes classes sociais (FÉLIX, 1984, p. 14). E a hipótese que guia o trabalho indica a AE com um papel principal de garantir ao Estado o controle sobre a educação, tendo em vista a crescente burocratização dos sistemas de ensino. Tal controle permitiria ao Estado adequar a educação ao seu projeto de desenvolvimento econômico e também seria condição para uma avaliação sobre os produtos da educação numa perspectiva da produtividade.

Félix apresenta as relações históricas entre o desenvolvimento do capitalismo e do sistema escolar no Brasil, encontrando suas interfaces. É um texto de recuperação da história da política educacional, mostrando as alterações na condução da política educacional ao longo do século XX no Brasil e buscando também discutir em que medida essas mudanças pelas quais passou o sistema escolar brasileiro têm relações com o incremento do capitalismo. A autora mostra que naquele movimento histórico se constituiu um processo de descaracterização da educação escolar, a partir da especialização, da divisão do trabalho e do controle exercido pelo poder público em relação às escolas. Essa descaracterização é responsável por tornar a escola mais e mais adaptada ao modo de produção típico do capitalismo monopolista.

Félix se volta, então, a discutir a cientificidade da administração escolar e da administração de empresa. A organização da ação produtiva dos trabalhadores é o objeto central sobre o qual se debruça a administração, pois segundo a autora é a partir dessa organização que a relação entre capital e trabalho, ou melhor, entre a exploração do trabalho pelo capital, se assenta e se mantém (FÉLIX, 1984, p. 35). E, para tanto, a administração lança mão da organização racional, da produtividade, da especialização do trabalho, dos mecanismos de controle na busca dos objetivos da empresa.

Assim, o campo da administração se constitui em um constante movimento entre a prática e a teoria (FÉLIX, 1984, p. 36), voltado a incrementar o processo produtivo em favor dos interesses do capital, e foi estudado pelas teorias clássicas da administração, que são seu objeto de crítica.

A autora afirma que as bases teóricas sobre as quais a administração escolar se solidifica são as teorias gerais da administração de empresas, pois a "Administração Escolar não construiu um corpo técnico próprio e no seu conteúdo podem ser identificadas as diferentes escolas da Administração de Empresa o que significa uma aplicação dessas teorias a uma atividade específica, neste caso, a educação" (FÉLIX, 1984, p. 71). Como confirmação desta tese a autora mostra textos de autores como Myrtes Alonso e José Querino Ribeiro, para os quais a administração escolar é uma especialidade da administração geral, e com ela compartilha os seus princípios e métodos.

Félix conclui indicando que a AE tem por função tornar a escola e o sistema de ensino em instituições cada vez mais burocratizadas, adequando-as ao modelo capitalista, através do controle do Estado, descaracterizando-as enquanto instituições a serviço da formação humana (Félix, 1984, p. 192). Mas, a autora, lembrando de G. Snyders, afirma que "a escola não é apenas a agência 'reprodutora' das relações sociais, mas o espaço em que se reproduz o movimento contraditório da sociedade que gera os elementos da sua própria transformação" (FÉLIX, 1984, p. 193). Isto é, a despeito das 
perspectivas teóricas da administração escolar no Brasil, a autora vê na escola potencialidades para a superação daquelas mesmas concepções.

A última obra deste período de crítica sobre a qual este artigo se debruça é a mais conhecida produção dos anos 1980 na área da administração escolar brasileira, e quiçá a mais conhecida produção da área até os dias atuais. Trata-se da tese de doutoramento de Vitor Paro, publicada em 1986, denominada "Administração Escolar: introdução crítica". Afirmando logo de início que o seu trabalho objetiva fundamentalmente "examinar as condições de possibilidade de uma Administração Escolar voltada para a transformação social" (PARO, 1988, p. 13), o autor procura demonstrar como as duas tendências então dominantes no pensamento da administração educacional brasileira de então estavam equivocadas. De uma parte, a concepção que advogava que a escola poderia ser administrada pelos mesmos procedimentos da empresa capitalista, e de outra, a concepção que avaliava ser desnecessário qualquer tipo de organização administrativa na escola; ambas incorriam no mesmo engano, segundo Paro, ao não levarem em conta que a administração escolar recebia decisivas influências dos determinantes sociais e econômicos, pois a

atividade administrativa não se dá no vazio, mas em condições históricas determinadas para atender a necessidades e interesses de pessoas e grupos. $\mathrm{Da}$ mesma forma, a educação escolar não se faz separada dos interesses e forças sociais presentes numa determinada situação histórica (PARO, 1988, p. 13).

O trabalho apresenta um panorama sobre a organização social e econômica da sociedade capitalista, focalizando particularmente os processos produtivos e as suas relações com a administração, de forma, ao cotejar esta análise com a organização e gestão escolar, a encontrar semelhanças entre aquelas formas de administração geral e as que ocorrem no espaço escolar, partindo do pressuposto que estas são análogas e/ou coincidentes.

"Administração é a utilização racional de recursos para a realização de fins determinados. Assim pensada, ela se configura como uma atividade exclusivamente humana" (PARO, 1988, p. 18). De posse deste conceito inicial, o autor avalia que a escola é, na visão da administração geral, mais uma instituição social que necessita ser coordenada por um dirigente que utilizará racionalmente os recursos disponíveis para assegurar-se da conquista dos objetivos almejados, como toda outra organização humana. Com alguma proximidade, portanto, do pensamento dos clássicos, especialmente Querino Ribeiro, Paro observa que a relação entre "uso racional" e "realização de fins determinados" é uma relação econômica, isto é, a busca para fazer com que os fins sejam alcançados no menor tempo possível e com um gasto mínimo dos recursos (PARO, 1988, p. 20). Para o autor, inicialmente trata-se dos recursos materiais e conceituais, que permitem a mediação do homem com a natureza no processo de racionalização do trabalho. Todavia, Paro ainda destaca que a administração olha para o trabalho humano como um recurso, mas, não o trabalho individual, pois a administração trata mesmo é das ações coletivas humanas, cuja utilização racional pela administração é denominada pelo autor de "coordenação do esforço bumano coletivo" (PARO, 1988, p. 23). À visão capitalista da administração que pensa no trabalho humano como recurso, o autor contrapõe-se, afirmando que o homem não pode ser recurso, pois é sempre, no limite, o próprio homem o fim de toda e qualquer atividade humana. Logo, a partir do entendimento dos recursos materiais e conceituais e das relações do trabalho coletivo humano, o autor afirma que a administração lida com dois campos que possuem interfaces entre si: a racionalização do trabalho e a as atividades de coordenação do trabalho coletivo (PARO, 1988, p. 24).

Após detalhada apresentação do pensamento de K. Marx sobre o processo de produção capitalista, Paro analisa tal processo e as formas administrativas ali constituídas para lhe darem suporte e condições de maior desenvolvimento econômico. E as relações entre o capitalismo e a 
administração se expressam na compreensão daquela racionalização do trabalho como uma ação que busca sempre o incremento da eficiência e da produtividade e, consequentemente, do lucro. De outro lado, tais relações também se expressam no entendimento da coordenação administrativa como uma função de controle dos trabalhadores, através da gerência (PARO, 1988, p. 58). Este processo de controle demanda, na sociedade capitalista, uma separação entre trabalho intelectual e trabalho manual, delegando àquele o planejamento e a gerência sobre as atividades deste e "É fundamentalmente dessa separação entre trabalho intelectual e manual, [...], que a gerência capitalista extrai as forças necessárias ao controle da atividade produtiva do trabalhador" (PARO, 1988, p. 63-64).

O autor passa, então, a discutir as questões sobre a transformação social, sustentando-se especialmente em Gramsci, buscando observar as formas pelas quais as pessoas tomam consciência acerca da organização social, econômica e política da sociedade, com vistas a transformá-la. Aqui, o autor se dedica pouco à análise da administração, pois está procurando articular a necessidade de superação do modelo social com os aspectos mais amplos da educação escolar, concluindo que a escola é potencialmente um espaço para a construção de tal movimento transformador e, para o qual, a atividade administrativa, pensada no seu caráter instrumental, é importante.

Ao final, Paro volta a tratar da administração, preocupando-se em relacionar as discussões anteriores com o ambiente escolar. $\mathrm{O}$ autor confirma sua avaliação de que a produção teórica sobre administração escolar no Brasil era basicamente sustentada nas equivocadas ideias de que a administração escolar era derivada da administração geral, pois era uma de suas aplicações e que os problemas educacionais eram originários da falta de tratamento administrativo adequado.

Esta visão é, segundo Paro, de flagrante conservadorismo em favor da manutenção das estruturas capitalistas na sociedade. Porém, o avanço técnico na direção das escolas, com vistas a torná-las mais eficientes e produtivas, poderia se voltar contra essa perspectiva conservadora. Isto é, os teóricos conservadores que defendem a aplicação de uma administração escolar tecnicamente avançada estariam contraditoriamente, contribuindo não para a conservação e sim para a transformação da sociedade. Mas, o autor registra que não é exatamente assim que as coisas funcionam no campo da administração escolar:

$\mathrm{Na}$ realidade concreta, entretanto, não é dessa forma que as coisas acontecem. Embora, no nível do discurso, se defenda a eficiência e racionalidade na obtenção dos objetivos - constituindo isso, inclusive, justificativa para a aplicação da administração tipicamente capitalista na escola -, no nível da ação, acabam por prevalecer apenas os mecanismos mais propriamente gerenciais, relacionados ao controle do trabalhador. Em outras palavras, o que a realidade de nossas escolas [...] revela é a vigência da dimensão mais especificamente política da administração capitalista, relativa ao controle gerencial do trabalho alheio, enquanto que os aspectos positivos de sua dimensão técnica permanecem obscurecidos, deixando de produzir os resultados esperados (PARO, 1988, p. 130).

Enquanto a teoria pregava o incremento dos aspectos técnicos na gestão das escolas, na prática da AE cotidiana o que parecia estar ocorrendo era um exagero nos processos normativos, no estabelecimento de elementos burocráticos e burocratizantes que mais impediam o desenvolvimento técnico da própria administração e mesmo político da escola e, consequentemente, a melhoria do trabalho e dos resultados pedagógicos deste trabalho.

A coordenação da política escolar, tarefa central da administração escolar, não dispensa o bom desempenho dos aspectos técnicos, ao contrário, deles depende. $\mathrm{O}$ autor confirma que este 
domínio técnico não deve ser confundido com "tecnicismo, que é a hipertrofia do aspecto técnico em detrimento dos demais, ou seja, é a utilização da técnica pela técnica, sem consideração para com os fins a que ela exatamente deve servir" (PARO, 1988, p. 159). A negligência técnica da administração escolar conservadora em favor de uma ação política também conservadora é a aplicação de um tecnicismo vazio de objetivos educacionais, isto é, este modelo de administração erra não na definição e construção de técnicas de gestão, mas na desvinculação dessa técnica dos reais objetivos escolares.

Por fim, Paro conclui afirmando que a AE transformadora não pode ignorar a realidade em que se encontra a organização das escolas, ao contrário, é partindo desta realidade que a transformação necessária emergirá, na qual a figura do diretor, então uma personagem central e de responsabilidade última pela escola, não pode ser ignorada e deve ser atraída para os compromissos de transformação social em busca.

Esses trabalhos do período do início dos anos 1980 têm algumas características bastante similares: a) estão todos voltados à crítica aos modelos de organização e gestão das escolas até então dominantes na literatura especializada e na prática escolar e educacional; b) são todos trabalhos com perfil teórico, ou de análise de produção teórica, são estudos conceituais (RIBBINS; GUNTER, 2002), não havendo, em nenhum desses casos articulação com pesquisas empíricas que tomassem a escola e a sua gestão como objeto de estudos; c) há um pressuposto para esses trabalhos: a AE como aplicação da administração científica nas escolas contribui para a manutenção das condições econômicas, sociais e políticas da sociedade; d) os instrumentos e processos da gestão escolar, como estavam sendo tratados pelos autores clássicos e como eram entendidos na organização prática das escolas são fenômenos essencialmente tecnocráticos, assim como o perfil do dirigente escolar, reconhecido por esses autores como de um gerente em uma empresa produtiva, cuja tarefa era de garantir a produtividade e o controle dos trabalhadores da educação.

Tais posicionamentos sugerem, em alguma medida, certo determinismo na análise da AE, explícito principalmente na obra de Félix. Mas, é Paro, apesar de somar-se a esta concepção, que auxilia a perceber as coisas de forma um pouco mais ampla, quando no início do seu trabalho afirma que a administração geral ou escolar não se dá no vazio (PARO, 1988, p. 13), pois sofre influência de várias frentes.

Ainda que pareça certo que os interlocutores dos autores críticos eram diretamente os diretores escolares nos anos 1970 e começo dos 1980 e os estudiosos do campo do período anterior, suas críticas também se destinavam ao período em que viviam, anos difíceis de ditadura militar, na qual tanto a política, como a educação eram operadas tecnocraticamente (SOUZA; TAVARES, 2014). É mesmo possível de se observar a relação e a dependência que ambos, diretores e estudiosos do campo, provavelmente tinham em relação ao modelo político e econômico de então. Assim, a crítica política à administração e à educação escolar intencionava atingir a organização de toda a sociedade.

A influência produzida pelos trabalhos do início dos anos 1980 é marcante (SOUZA, 2007; TAVARES, 2004). E ela também parece ser importante para a compreensão da natureza e do campo de conhecimentos da administração escolar: uma natureza política, antes de tudo.

\section{As influências}

Os tópicos anteriores apresentaram os principais estudos sobre a gestão escolar no Brasil, do nascedouro do campo temático até os anos 1980, época de marcante crítica aos modelos de 
organização e administração aplicados nas escolas. A análise das influências desses estudos sobre a gestão escolar atual decorre do confronto entre aquelas teorias e estudos contemporâneos sobre o conhecimento do campo, como Abdian (2010; 2016), Abdian, Andrade e Paro (2017), Barroso (2009), Martins e Sousa (2012), Souza (2006; 2007).

A pesquisa no campo, a partir dos anos 1980, segundo esta literatura, herdou importantes marcas daquela crítica, destacadamente: a) o reconhecimento da gestão escolar como um processo político-pedagógico; b) a preocupação com temas até então pouco importantes, como a democratização da gestão escolar. Todavia, mesmo sendo possível se afirmar que o período da crítica à escola clássica da gestão escolar inspirou uma sequência de estudos na área durante as décadas de 1980 a 2000, é também possível se observar o surgimento de novos temas e abordagens nas pesquisas na área. E isto está relacionado com a realidade empírica experimentada pelas escolas, uma vez que é evidente o crescimento de estudos de natureza empírica no campo a partir dos anos 2000.

Isto quer dizer que a produção acadêmica brasileira sobre gestão escolar nos últimos 25 anos parece ter trilhado os caminhos apontados pelos temas específicos que estavam na pauta do dia (SOUZA, 2006, 2007). Há uma ampliação significativa de temas e abordagens com o avançar dos anos, destacadamente as questões referentes ao conselho escolar e ao projeto políticopedagógico enquanto instrumentos da organização e gestão escolar; os diferentes modelos de gestão com as devidas apreciações e avaliações; as faces e desafios da gestão democrática; os elementos cotidianos do poder, da cultura escolar e dos processos de gestão; os desafios da autonomia e da descentralização; dentre vários outros.

Há, ainda, problemas nessa produção, em especial no que se refere à ênfase por vezes um tanto normativa de vários trabalhos sobre gestão escolar (SOUZA, 2007; TAVARES, 2004), particularmente sobre os conselhos de escola e sobre a gestão democrática, que se dedicam mais a demonstrar como a escola deve se organizar para ser democrática e menos a descrever e analisar como ela tem se organizado, democrática ou não.

De qualquer forma, a impressão que se tem ao olhar o campo da gestão escolar, desde a primeira metade do século XX até hoje, é que o conhecimento nesta área caminhou pela trilha dos reclames pela sua profissionalização e adoção de paradigmas técnicos advindos da teoria geral da administração de empresas e da importação da teoria da administração escolar norteamericana; passou pelas preocupações mais pedagógicas com a complexificação do fazer escolar; enfrentou criticamente os problemas decorrentes daquelas importações teóricas e; perspectivou um futuro mais democrático para as escolas públicas no que tange à sua gestão.

Contudo, este suposto por-vir democrático parece ainda não vingado, ao menos na investigação científica. Há, em parte considerável da produção, um compasso de espera por novas teorias, por trabalhos que apontem novos rumos (Souza, 2007; Souza, 2009b). Enquanto isto, a pesquisa caminha mais próxima dos casos empíricos, relatando casos de democratização da gestão escolar e, em muitas vezes, normatizando ou prescrevendo as formas pelas quais as escolas devem se orientar para alcançarem aquele por-vir. Esta preocupação sobre o que deve a escola fazer para resolver os seus problemas de gestão parece inata aos estudos sobre a temática, pois o campo da administração (em geral) quase sempre se caracterizou por migrar da prática à teoria, e desta para aquela (FÉLIX, 1984), pois esteve dominantemente articulado com o funcionamento prático das instituições. As soluções para os problemas da gestão escolar continuam desconhecidas, contudo. Mas, os problemas já são melhor conhecidos, e isto se deve ao acumulo resultante da ampliação de estudos, de objetos de estudos e pelas novas abordagens desses problemas de pesquisa. 
A produção analisada, ao longo do século XX e começo do XXI, compreende que o diretor é um educador que tem a tarefa de coordenar o esforço coletivo desenvolvido na escola, pois a gestão escolar é, antes de tudo, a coordenação deste trabalho com vistas aos objetivos educacionais.

Vimos que há sentidas diferenças entre os períodos de estudo e proposição da gestão escolar, mas parece que há um relativo consenso no reconhecimento do diretor como sujeito que está no centro das relações de poder escolares. Nos estudos clássicos, este reconhecimento condiz com as concepções próprias do período acerca da função de dirigente escolar. Mais do que isto, neste período o diretor não era visto apenas no centro do poder, como principalmente o concentrador do poder. Nos estudos críticos, há divergência com esta naturalização da centralização do poder nas mãos do dirigente escolar. Ademais, estes autores compreendem que o diretor é tratado como um preposto do Estado capitalista e que tem a tarefa de gerenciar o trabalho coletivo. Hodiernamente, parece haver um reforço na compreensão do diretor como um amplo articulador das relações educacionais e de outras naturezas, mas que se relacionam com àquelas, que tem lugar na escola (SOUZA, 2006).

Somando-se a isto, estudos mais recentes (SOUZA; GOUVEIA, 2010; PARO, 2010) mostram que os diretores atendem aos interesses dos diferentes segmentos como estratégia política de sobrevivência, modificando inclusive suas aparentes concepções para se conservar no centro da cena política. Atender aos interesses dos superiores hierárquicos e aos da comunidade escolar faz parte deste jogo político. Isto condiz, ao que tudo indica, com as concepções de todos os períodos, pois não parece haver controvérsias sobre a existência de uma face política do diretor escolar. Desde Carneiro Leão até os estudos mais recentes, o diretor é reconhecido, ainda que não tendo esta face como a principal, como um sujeito que desempenha uma função que tem alguma natureza política. A diferença entre os autores recai sobre a serviço de que $(\mathrm{m})$ esta face política do diretor escolar deve se posicionar.

É possível mais um destaque nas diferenças entre esses períodos no que tange à natureza política da função de diretor escolar. Refere-se à imbricação e mescla entre os conceitos de direção e gestão escolar. No período clássico, havia uma menor separação entre pessoa e processo dirigente. Apesar dos esforços dos autores deste período em conceituar a administração escolar, não houve esforço maior sobre a conceituação da direção escolar. Nos períodos seguintes, esta separação parece melhor identificada. No cotidiano das escolas, parece que há um pouco de cada concepção, na medida em que tanto encontramos experiências alargadas de horizontalidade e democratização na gestão escolar, com a plena separação entre diretor e gestão, como ainda é comum, especialmente nas escolas cujos diretores foram indicados politicamente, vermos a gestão subsumida ao diretor, confundindo-se pessoa e processo (SOUZA, 2006).

Outro elemento importante de ser destacado se refere à outra possível contradição, entre as faces administrativa e pedagógica da função de diretor. Para os autores do período clássico não parece restar dúvidas: o diretor tem um papel administrativo e institucional que se centra, em larga medida, na ação pedagógica desenvolvida na escola. Isto é, sua função é justamente por meio da ação administrativa dar as condições adequados para o desenvolvimento das ações pedagógicas. Contudo, a ênfase nesta ação administrativa levou os autores críticos a se posicionarem contrariamente àquela concepção e a perceberem aquelas faces como contraditórias, não em sua essência, mas na ação prática dos diretores. Pesquisas mais recentes (PARO, 1995; OLIVEIRA, 2015; SOUZA, 2006, 2010) indicam que os diretores estão se dedicando mais às ações administrativas do que às ações pedagógicas, o que, de certa forma, confirma a concepção da escola clássica, e, por isto, confirma a crítica dos autores do período seguinte. Todavia, a natureza da função não parece ser de uma contradição entre aquelas faces. Se 
isto ocorre é possivelmente por pressão exercida sobre o diretor para que priorize as ações mais administrativas, stricto sensu, ou por opção/concepção própria. Em qualquer dos casos, parece haver um problema: uma menor centralidade pedagógica na ação do dirigente escolar.

Um último aspecto diz respeito à ideia de que a gestão é um processo que recai sobre a ação coletiva, que, como vimos, também está presente nos períodos analisados. Na literatura mais recente, para além dos dois períodos, isto se expressa pelo surgimento e/ou aprofundamento da temática da gestão democrática ${ }^{6}$. As escolas possuem Conselho Escolar (CE) e Projeto PolíticoPedagógico (PPP). Os CE funcionam minimamente e os PPP têm a participação dos professores na sua construção (SOUZA, 2007), o que pode indicar que há avanços no sentido da ampliação da democracia na gestão escolar, porque a simples existência e crescimento desses instrumentos e processos já permitem compreender que há mais espaço para o desenvolvimento da gestão democrática. É certo que são apenas instrumentos que potencializam a democratização da gestão escolar, mas são indicadores também das condições e do ambiente democrático (SOUZA, 2009, 2017).

Em síntese, apesar de várias semelhanças, o perfil e as práticas do diretor escolar não se equivalem plenamente ao prescrito no período clássico, porque o diretor não é um administrador no sentido mais estrito, nem conduz um processo essencialmente técnico-administrativo que é a gestão escolar. Mas, também, não condiz com as avaliações do período da escola crítica, no qual o diretor era denunciado como um gerente do estado capitalista (SOUZA, 2006). De outro lado, a existência e funcionamento do CE, a existência e construção do PPP, as formas de provimento de diretores, assim como a participação comunitária e as relações políticas na/da escola, denunciam a natureza dominantemente político-pedagógica da direção e da gestão escolar, pouco trabalhada pelos dois períodos no campo, e enfatizada pela literatura mais recente, a qual parece mais articulada com os movimentos do cotidiano escolar do que os estudos dos períodos anteriores.

\section{Conclusão}

Parece haver certa desarticulação entre as ideias sobre a gestão escolar ao longa da história e a figura atual do dirigente e da gestão escolar. Isto pode ser articulado aos seguintes fatores: (a) aquelas teorias estão debatendo um outro contexto e um outro tempo da organização e gestão da escola, nos quais havia nas escolas outros problemas e com outros graus de complexidade, consequentemente os dirigentes e os processos de gestão que comandavam tinham outro perfil, mas, é necessário que se destaque que aquela desarticulação também se deve, e talvez principalmente, (b) à constatação de que não são estudos empíricos, isto é, não trabalharam com o que de fato existe(ia) nas gestões escolares no país. Se isto é verdade para os dois períodos analisados, de outro lado pode estar mudando mais recentemente (ABDIAN et al., 2016), pois há um número maior de pesquisas indo às escolas, conhecendo-as por dentro e tendo mais condições de identificar, bem de perto, quem são os dirigentes escolares e como se organizam as escolas quanto aos processos de gestão (OLIVEIRA, 2015; SOUZA, 2007).

Em que pese esta desarticulação, há influências das teorias descritas e a realidade da gestão escolar atual. E isto é devido ao fato de que os estudos científicos não são voltados apenas à descrição e análise do mundo real. A ciência também modifica o mundo, pois interfere no

\footnotetext{
${ }^{6}$ É sabido que a gestão democrática não surgiu após 1980, mesmo porque os autores do período clássico já faziam referências a questões que poderiam se articular com a democratização da gestão da educação. Todavia, a presença sistemática deste tema na ordem do dia das pesquisas e trabalhos acadêmicos no campo da gestão escolar ocorreu naquele período (SOUZA, 2007).
} 
mundo apresentando suas teses, hipóteses e sínteses que, se não explicam como as coisas são/acontecem, interagem com os fenômenos e sujeitos reais, responsáveis por aquelas coisas, a ponto de sugerir como o mundo deveria se organizar. $\mathrm{Na}$ educação, em particular na gestão educacional e escolar, a pesquisa tem esta forte marca normativa (SOUZA, 2007). A prescrição apresentada pelos estudos brasileiros sobre a gestão escolar produzidos ao longo do século XX, tem a força do poder acadêmico (BOURDIEU, 1998) e do poder do discurso competente (CHAUÍ, 1997) e é capaz de moldar as pessoas e as suas formas de agir na condução das escolas públicas. De outro lado, a teoria no campo da gestão escolar apresenta alternativas para a solução de problemas que são utilizadas pelos sistemas de ensino e pelas escolas, de sorte que na medida em que o modelo prescrito seja adotado, o perfil da gestão e do dirigente pode acabar se assemelhando àquela prescrição.

\section{Referências}

Abdian, G. Z. (2010). As publicações da ANPAE e a trajetória do conhecimento em Administração da educação no Brasil. Revista Brasileira de Política e Administração da Educação, 40, $31-50$.

Abdian, G. Z., Nascimento, P. H. C. \& Silva, N. D. B. (2016). Desafios teórico-metodológicos para as pesquisas em administração/gestão educacional/escolar. Educação \& Sociedade, 37 (135), 465-480.

Abdian, G. Z., Andrade, E. \& Parro, A. L. G. (2017). Sentidos de política e/de gestão nas pesquisas sobre a escola. Educaşão \& Pesquisa, 43 (3), 727-742.

Arroyo, M. G. (1979). Administração da educação, poder e participação. Educação e Sociedade. 1 (2), $36-46$.

Barroso, J. (2009). A utilização do conhecimento em política: o caso da gestão escolar em Portugal. Educação \& Sociedade, 30 (109), 987-1007.

Bourdieu, P. (1998). Escritos de educação. Petrópolis: Vozes.

Chauí, M. (1997). Cultura e democracia: o discurso competente e outras falas. São Paulo: Cortez.

Drabach, N. P. (2009). Primeiros Escritos sobre Administração Escolar no Brasil aos escritos sobre gestão escolar: mudanças e continuidade. Monografia (Especialização em Gestão Educacional) - Universidade Federal de Santa Maria, Santa Maria.

Félix, M. F. C. (1984). Administração escolar: um problema educativo ou empresarial? Análise da proposta do estado capitalista brasileiro para a burocratização do sistema escolar. São Paulo: Cortez/Autores Associados.

Leão, A. C. (1953). Introdução à administração escolar (3a ed.). São Paulo: Cia. Editora Nacional.

Martins, A. M. \& Sousa, S. Z. (2012). A produção científica sobre avaliação educacional e gestão de sistemas e de escolas: o campo da questão entre 2000 e 2008. Ensaio: avaliação e políticas públicas em educaşão, 20 (74), 9-26. 
Oliveira, A. C. P. (2015). As relações entre Direção, Liderança e Clima Escolar em escolas municipais do Rio de Janeiro. Tese de Doutorado em Educação, Pontifícia Universidade Católica do Rio de Janeiro, Rio de Janeiro, RJ, Brasil.

Paro, V. H. (1988). Administração escolar: introdução crítica. São Paulo: Cortez; Autores Associados.

Paro, V. H. (1995). Por dentro da escola pública. São Paulo: Xamã.

Paro, V. H. (2010). A educação, a política e a administração: reflexões sobre a prática do diretor de escola. Educação \& Pesquisa, 36 (3), 763-778.

Ribbins, P. \& Gunter, H. (2002). Mapping leadership studies in education. Educational management \& administration. 30 (4), 359-385. Londres: Sage Publ.

Ribeiro, J. Q. (1952). Ensaios de uma teoria da administração escolar. São Paulo: USP.

Ribeiro, D. S. \& Machado, L. M. (2007). Teorias de Administração Escolar em Querino Ribeiro e Lourenço Filho: raízes e processos de constituição de modelos teóricos. Revista Brasileira de Política e Administração da Educação, 23, 13-28.

Sander, B. (1981). Administração da Educação no Brasil: evolução do conhecimento. Brasília: ANPAE/Edições UFC.

Sander, B. (1984). Consenso e conflito: perspectivas analíticas na pedagogia e na administração da educaşão. São Paulo: Pioneira.

Souza, A. R. (2006). Os dirigentes escolares no Brasil. Educaşão: Teoria e Prática, 15 (27), 51-82.

Souza, A. R. (2007). Perfil da gestão escolar no Brasil. Tese de Doutorado. Pontifícia Universidade Católica de São Paulo, São Paulo, SP, Brasil.

Souza, A. R. (2009b). A pesquisa no campo da Gestão da Educação: algumas reflexões sobre as relações entre produção doconhecimento e a prática da gestão educacional. Retratos da Escola, 3 (4), 81-94.

Souza, A. R. (2009). Explorando e construindo um conceito de gestão escolar democrática. Educaşão em Revista, 25 (3), 123-140.

Souza, A. R. (2017). As condições de democratização da gestão da escola pública brasileira. Anais do XIII Educere - Congresso Nacional de Educaşão. Curitiba, PR, Brasil: Pontifícia Universidade Católica do Paraná.

Souza, A. R. \& Gouveia, A. B. (2010). Diretores de escolas públicas: aspectos do trabalho docente. Educar em Revista, número especial (1), 173-190.

Souza, A. R.; Tavares, T. M. (2014). A gestão educacional no Brasil: os legados da ditadura. Revista Brasileira de Política e Administração da Educação, 30 (2), 269-285. 
Tavares, T. M. (2004). Gestão pública do sistema de ensino no Paraná (1995-2002). Tese de Doutorado em Educação: Currículo, Pontifícia Universidade Católica de São Paulo, São Paulo, SP, Brasil.

Teixeira, A. (1961). Que é administração escolar? Revista Brasileira de Estudos Pedagógicos. Rio de Janeiro, 36 (84), 84-89.

Teixeira, A. (1968). Natureza e função da administração escolar. In TEIXEIRA, A. et al. Administração Escolar. Salvador: ANPAE.

Tragtemberg, M. (1974). Burocracia e ideologia. São Paulo: Ática.

Recebido: 30/07/2017

Aceito: $18 / 10 / 2017$

Publicado online: $24 / 10 / 2017$

\section{Ângelo Ricardo de Souza}

Doutor em Educação (PUC-SP). Professor e pesquisador do Núcleo de Políticas Educacionais (NuPE) e do Programa de Pós-Graduação em Educação (PPGE) da Universidade Federal do Paraná (UFPR). 